\title{
Communication
}

\section{Investigating the Impacts of Landuse-landcover (LULC) Change in the Pearl River Delta Region on Water Quality in the Pearl River Estuary and Hong Kong's Coast}

\author{
Yuanzhi Zhang ${ }^{1{ }^{*}, \text { Yufei Wang }}{ }^{1}$, Yunpeng Wang ${ }^{2}$ and Hongyan $\mathrm{Xi}^{1}$ \\ 1 Institute of Space and Earth Information Science, The Chinese University of Hong Kong, Shatin, \\ Hong Kong, China; E-Mails: wangyufei@cuhk.edu.hk (Y.W.); hongyanxi@cuhk.edu.hk (H.X.) \\ 2 Guangzhou Institute of Geochemistry, Chinese Academy of Sciences, 510640 Guangzhou, \\ Guangdong, China; E-Mail: wangyp@gig.ac.cn
}

* Author to whom correspondence should be addressed; E-Mail: yuanzhizhang@cuhk.edu.hk; Tel.: +852 31634409; Fax: +852 26037470.

Received: 15 October 2009; in revised form: 11 November 2009 / Accepted: 16 November 2009 / Published: 17 November 2009

\begin{abstract}
Water quality information in the coastal region of Hong Kong and the Pearl River Estuary (PRE) is of great concern to the local community. Due to great landuse-landcover (LULC) changes with rapid industrialization and urbanization in the Pearl River Delta (PRD) region, water quality in the PRE has worsened during the last 20 years. Frequent red tide and harmful algal blooms have occurred in the estuary and its adjacent coastal waters since the 1980s and have caused important economic losses, also possibly threatening to the coastal environment, fishery, and public health in Hong Kong. In addition, recent literature shows that water nutrients in Victoria Harbor of Hong Kong have been proven to be strongly influenced by both the Pearl River and sewage effluent in the wet season (May to September), but it is still unclear how the PRE diluted water intrudes into Victoria Harbor. Due to the cloudy and rainy conditions in the wet season in Hong Kong, ASAR images will be used to monitor the PRE river plumes and track the intruding routes of PRE water nutrients. In this paper, we first review LULC change in the PRD and then show our preliminary results to analyze water quality spatial and temporal information from remote observations with different sensors in the coastal region and estuary. The study will also emphasizes on time series of analysis of LULC trends related to annual sediment yields and critical source areas of erosion for the PRD region since the 1980s.
\end{abstract}


Keywords: LULC; water quality; PRD; Hong Kong

\section{Introduction}

Remote sensing technique is a valuable tool to obtain information about processes that take place on the surface of waters [1,2]. One major advantage of satellite remote sensing observations over traditional measurements of water quality monitoring is that they provide both spatial and temporal data of surface water characteristics. With current satellite-based advanced sensors, a large amount of water quality information, such as chlorophyll-a (Chl-a), suspended particle matter (SPM), yellow substance, turbidity, Secchi disk depth, wave height, color index, and sea surface temperature (SST), can be observed on a regular basis $[3,4]$. However, there are still some outstanding issues related to the performance of the atmospheric correction in the coastal areas [5], especially due to the effects of turbid waters in coastal regions and river estuaries.

Several studies have addressed the importance of accurately acquiring the information of water components for water quality monitoring by using remote sensing. Since the 1970s, a large number of satellites have been launched with multi-sensors onboard, which are providing data to various databases all the time. Numerous studies on water quality monitoring in different regions of the world have been initiated via different methods and instruments. River estuaries and coastal margins are the areas of most concern due to their complex hydrological environment, particular physical and biochemical properties of water body [6-8]. A series of studies on SPM around the Mississippi River and Gulf of Mexico have been done [9-11], and satellite remote sensing of ocean color has been used to study coastal processes such as spatial and temporal variability of SPM around this area, as well as in the Urdaibai Estuary of Spain [12]. Accurate remote assessment of chlorophyll-a concentration can be retrieved in turbid, productive estuaries such as the Chesapeake Bay [13].

In China, attention has focused on the coastal areas around the Yangzte River mouth and the Pearl River estuary (PRE) [14]. Results include a three-dimensional model of the PRE suspended solids by coupling with the three-dimensional hydrodynamic model [15], the SPM impacts on the PRE and the analysis of its 25-year transition based on Landsat TM images [16], and the suspended sediment concentration in PRE and its adjacent coastal waters from 1995-2000 based on NOAA/AVHRR data [17]. A recent study of water quality assessment from satellite data is reported by using the composite pollution index (CPI) calculated from the measured chemical oxygen demand (COD) and nutrient concentrations. The distribution of water quality levels from the CPI calculation was retrieved from SeaWiFs water-leaving radiance [18]. These studies not only show that the spatial distribution of nutrients, phytoplankton biomass, and dissolved oxygen is highly related to the PRE dynamic interaction with adjacent coastal waters $[19,20]$, but also indicate that water nutrients in Hong Kong's Victoria Harbor are strongly influenced by the PRE discharge and sewage effluent in the wet season from May to September [21,22]. These research results show that obvious spatial distribution and temporal variation existed, but the concentrations of water components are changing all the time from the river mouth to the open sea.

Although there are some reports on water quality parameters distribution and dynamics in the PRE region, chlorophyll-a variation and transition have been little studied on a long-term basis. Previous 
research implies that landuse-landcover (LULC) change has some correlation with SPM movement along the coastal waters, but there is no analysis of how LULC trends might influence annual sediment yields and critical source areas of erosion for the PRE watersheds. In particular, retrieval algorithms development and time series of analyses by using multi-satellite data have not been addressed in previous studies. We will show some preliminary results in this paper.

\section{Study Area}

The coastal region around Hong Kong and the Pear River estuary (PRE) is selected as our study area (see Figure 1).

Figure 1. The study area in the PRE and coastal region of Hong Kong (adopted from MapPoint).

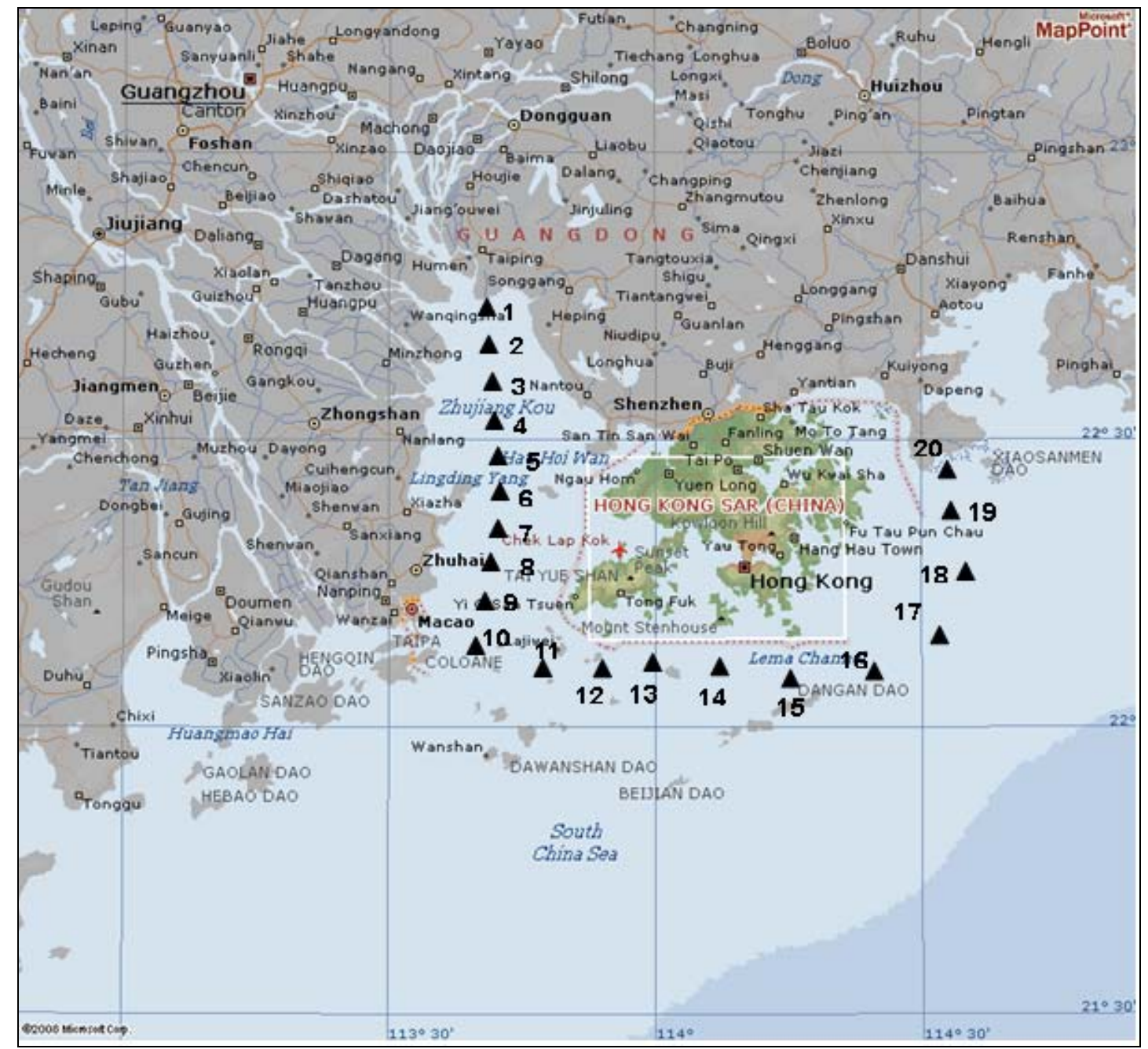

The Pearl River Delta region has experienced rapid economic growth since the 1980s. Along with the economic development, great changes on land use status have taken place. Up to 1998, the urbanization level of this region was $47 \%$, which is far higher than the $25 \%$ of the rest of the country. Rapidly urbanization development must come along with the rapid population growth and urban area expansion. So the economic development in Pearl River Delta region is closely linked with human activities, which have given rise to the increasing pollution problems and the serious pressure on water 
quality. The fast land use change in this region can inevitably further worsen the water quality in Pearl River estuary and its adjacent waters, including Hong Kong coastal waters. Therefore, it is significant to study the land use change in Pearl River Delta area and its environmental effects on water quality.

Figure 2. Flowchart of the proposed research.

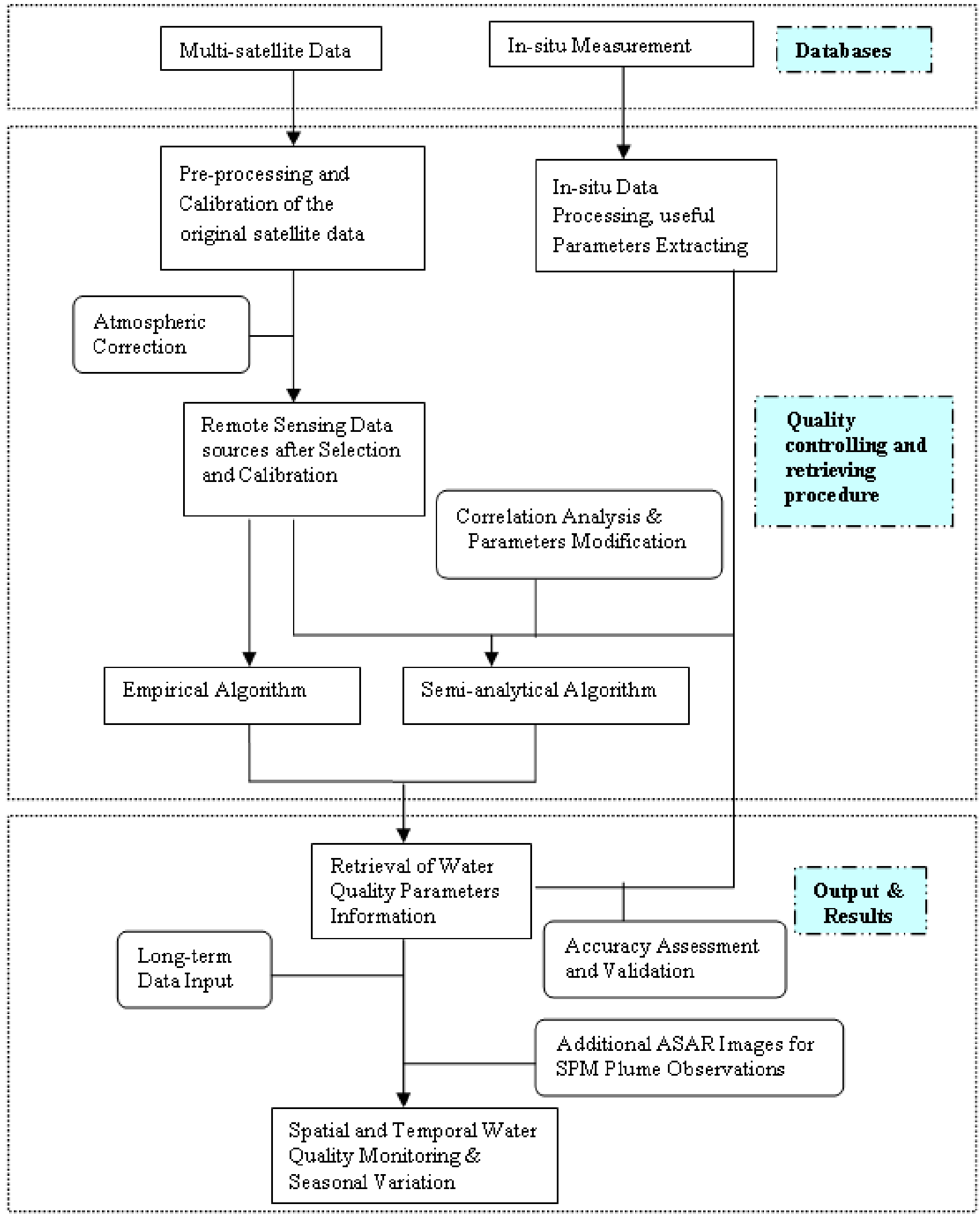




\section{Data Collection and In Situ Measurements}

Remote sensing data are collected from several optical sensors, while MODIS and MERIS are the main two sensors used due to their convenient availability and the fact they are charge-free. MODIS, which is onboard both EOS Terra and Aqua satellite, can provide data from the same region twice a day. MODIS has 36 spectral bands and three different spatial resolutions, which is ideal for monitoring large time scale changes in both open sea and coastal regions. Moreover, the simultaneous acquisition of MERIS and ASAR data is available on board the ENVISAT launched in 2002, making it possible to evaluate water quality information in the coastal regions with either cloud-free or all-weather conditions. Unlike MODIS data, MERIS products have a higher resolution than MODIS and are easy to process using the special BEAM processing software.

MODIS and MERIS data in different months or at least four different seasons of the year will be collected and processed. However, due to local cloudy and rainy conditions, atmospheric correction and cloud elimination are necessary before data preprocessing and geo-calibration. A new atmospheric correction was approached by using MODIS short wave infrared (SWIR) bands for deriving more accurate ocean color products in coastal regions [5]. With this newly developed calibration method, the ocean color images in the coastal waters, so called case 2 waters, can be better calibrated. The method will be applied in our case studies. After data preprocessing, suitable quantity of MODIS and MERIS data will be selected for the examination and application of two existing algorithms in other tasks. High spatial and spectral resolution images, such as ALOS and Hyperion data, will also be purchased and preprocessed to test the existing algorithms used in other tasks.

In addition, we collected marine water data at 67 stations from Environmental Protection Department (EPD) of Hong Kong Special Administration Region (HKSAR) and preprocessed the data to be used in other tasks.

The optical properties of coastal waters were investigated from a floating platform to measure the field spectra of water stations. Concurrent water sampling and samples analysis in the laboratory were performed in May and August 2008. The position of the sampling boat was be geo-located by a portable Global Position System (GPS), and 15 20 stations were be sampled in each cruise. In situ field spectral data were measured simultaneously. At each station, data measurements include field spectra, IOPs, water temperature, salinity, suspended particle matter (SPM), chlorophyll-a (Chl-a), pH, TN, TP, COD, and BOD. These datasets were preprocessed to prepare for the use of the algorithm development and validation. Figure 2 shows the flowchart of the proposed research.

\section{Methods}

\subsection{Retrieval of Suspended Particulate Matter (SPM) Concentrations}

The empirical two-band ocean color remote sensing reflectance algorithm $\left(\mathrm{R}_{\mathrm{rs}} \lambda_{1} / \mathrm{R}_{\mathrm{rs}} \lambda_{2}\right)$ will be used in practice for retrieving SPM concentrations, where $\lambda_{1}$ is usually around the red band and $\lambda_{1}$ is around the green band. Recent literature has suggested that the reflectance ratios $R_{\mathrm{rs}} 670 / \mathrm{R}_{\mathrm{rs}} 555$ of SeaWiFS data were highly correlated to SPM concentrations by using the coincident field data in Mississippi River estuary and coastal waters [9-10]. This relationship can also be expressed as: 


$$
\mathrm{SPM}=\mathrm{A} *\left(\mathrm{R}_{\mathrm{rs}} 670 / \mathrm{R}_{\mathrm{rs}} 555\right)^{\mathrm{B}}
$$

Similarly, MODIS and MERIS sensors have similar bands to receive water surface reflectance. Thus, Equation (1) can be written as:

$$
\mathrm{SPM}=\mathrm{A} *\left(\mathrm{R}_{\mathrm{rs}} \mathrm{Red} / \mathrm{R}_{\mathrm{rs}} \text { Green }\right)^{\mathrm{B}}
$$

where A and B are empirical coefficients and can be determined through the combined analysis of in situ measurements and field spectral data.

\subsection{Retrieval of Chlorophyll-a (Chl-a) Concentrations}

The three most popular Chl-a algorithms are the empirical, semi-analytical and analytical methods. The empirical method is based on a large amount of field in situ datasets, by which the statistical relationships of Chl-a and remote sensing reflectance can be found. Although it is very suitable for open ocean waters, this approach is not useful for turbid coastal waters. In comparison, the analytical approach is used to derive Chl-a from radiative transfer functions, however it is still too sophisticated to improve the whole model from the basis part and obtain the solutions exactly.

In this study, the semi-analytical method will be applied and developed. The technique is based on the relationship between reflectance $R(\lambda)$ and two inherent optical properties (IOPs), total absorption (a) and backscattering $\left(b_{b}\right)$ coefficients [23]:

$$
\mathrm{R}(\lambda) \propto \gamma \frac{b_{b}(\lambda)}{a(\lambda)+b_{b}(\lambda)}
$$

where $\gamma$ is dependent on the geometry of the light field emerging from the water body.

The total absorption coefficient can be expressed as:

$$
a(\lambda)=a_{w}(\lambda)+a_{\phi}(\lambda)+a_{g}(\lambda)+a_{d}(\lambda)
$$

where $\mathrm{w}, \varphi, \mathrm{g}, \mathrm{d}$ stand for pure water, phytoplankton, yellow substances and suspended particles, respectively.

The total backscattering coefficients can be written as:

$$
b_{b}(\lambda)=b_{b w}(\lambda)+b_{b p}(\lambda)
$$

A recent literature suggests that the accurate assessment of Chl-a concentrations in turbid case 2 waters by means of remote sensing can be made by three spectral bands [24]:

$$
\text { Chla } \propto\left[R^{-1}\left(\lambda_{1}\right)-R^{-1}\left(\lambda_{2}\right)\right] \times R\left(\lambda_{3}\right)
$$

In the study, the three-band algorithm will be applied and validated by in situ measurements and field datasets.

\section{Preliminary Results}

MERIS with 300-1,200 m resolution provides global coverage every three days, and can therefore be used to retrieve water quality information twice a week. MODIS data with 250-1,000 m resolution covers the PRE and coastal region of Hong Kong on a daily basis, and is free of charge. The MODIS 
data will be used to produce the daily water quality information in the study area. However, ALOS and Hyperion data with 10-30 m resolutions will be applied to test and validate the developed algorithms in the study. As a result, the spatial distribution of SPM and Chl-a in the PRE and coastal region of Hong Kong will be mapped weekly, monthly, and seasonally from multi-sensors optical data. Figure 3 shows our preliminary results in the study area using MERIS data.

Figure 3. Spatial distribution of SPM and Chl-a in the study area using MERIS data.
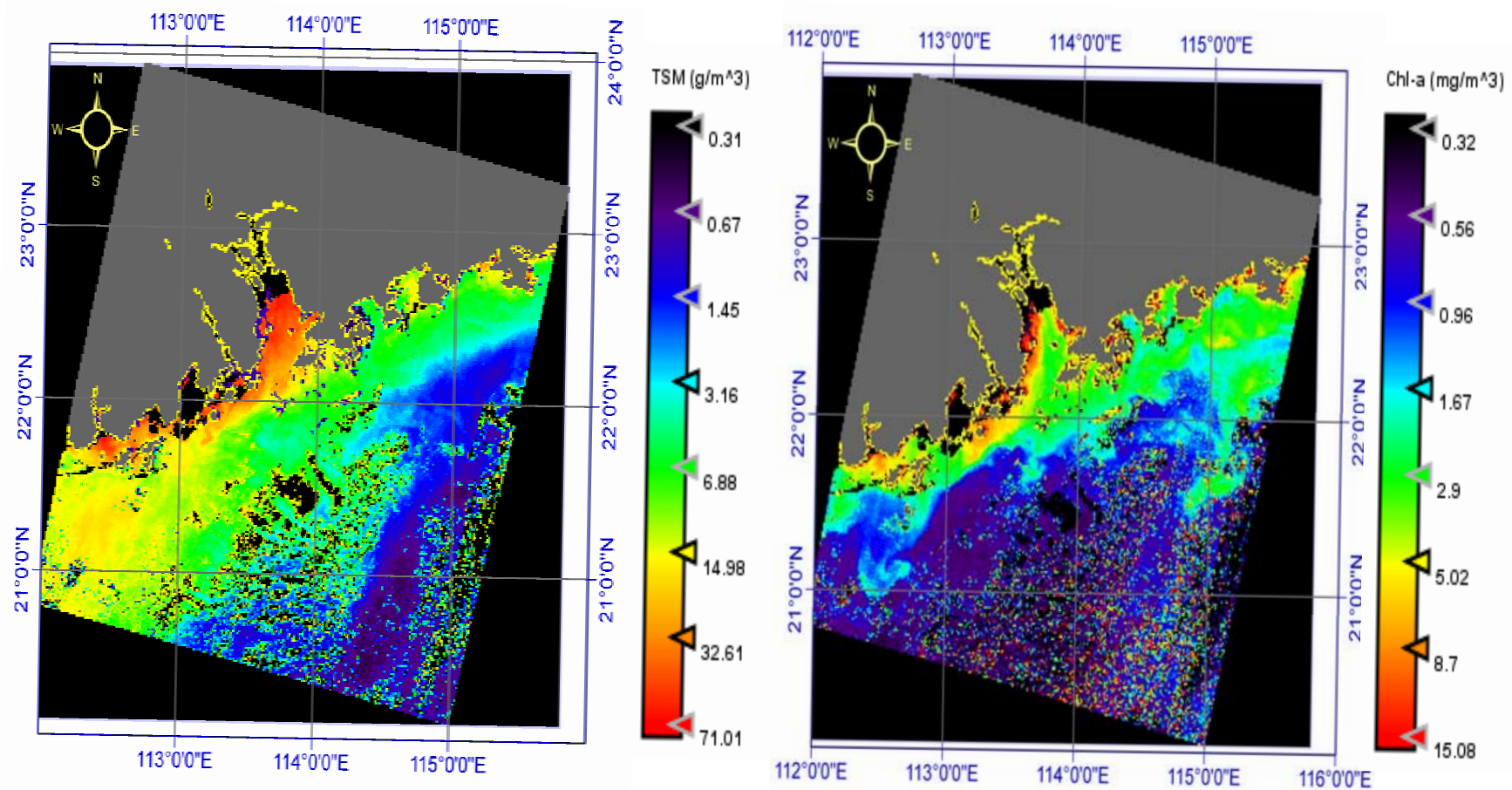

\section{Future Tasks}

\subsection{Additional Use of Radar Images}

In this task we will explore to use radar images for additional satellite observations. Due to the all-weather capability of radar images, Advanced Synthetic Aperture Radar (ASAR) images will be used to monitor the features of SPM plumes in the PRE in summer cloudy conditions and track the intruding route of SPM plumes into the coastal water of Hong Kong. Water nutrients in Hong Kong's Victoria Harbor have been shown to be strongly influenced by both the Pearl River plumes and sewage effluent in the wet season from May to September [21,22], but it is still unclear how the PRE plumes intrude into Victoria Harbor. Therefore, five ASAR images from May to September will be processed to extract the information of the PRE plumes and determine whether the ASAR images can be used to monitor the PRE plumes.

\subsection{Accuracy Assessment and Error Analysis}

When the algorithms of SPM and Chl-a concentrations have been developed and established based on previous studies and current research work, it will still be necessary to assess their accuracy. Part of 
the datasets collected from EPD of HKSAR and our field measured data of water samples will be used to evaluate the accuracy. The rest of the datasets will be used to verify the advanced algorithms via calculating standard errors and comparing with previous results. The deviation of the algorithm should also be analyzed in the study.

\subsection{LULC Trends Analysis}

Support vector machines (SVMs) will be applied to analyze LULC change trends in the Pearl River Delta (PRD) region [25]. The previous studies and recent results of LULC changes will be used to compare with the annual sediment yields and critical source areas of erosion for the PRD region since the 1980s, by which the annual characteristics of water quality in the study area and its spatial and temporal variation can be further understood.

\subsection{Impacts of LULC Trends on PRE Sediments}

PRE sediment features will be analyzed to determine how LULC trends influence on its annual yields and critical source areas of erosion for the PRD region. The eventual goals that we will achieve are to understand how SPM vary seasonally and annually. With the analysis of LULC trends since the 1980s, the sediment supply in the PRD region and the SPM spatial distribution in the PRE should be better understood. The seasonal SPM variability should be highly affected by the PRE discharge in wet and dry seasons. However, annual variation of SPM still needs to be further analyzed and then compared with LULC trends from the previous studies and current research output, and finally to show how the change trend of LULC with a rapid industrialization and urbanization in the PRD region impacts on PRE sediment features.

\section{Acknowledgements}

The authors would like to thank the Direct Grants (No. 2020928) at the Chinese University of Hong Kong and GRF 2120344 (RGC CUHK454909) to support this research. They also thank ENVISAT for providing the MERIS data used in the study. Two reviewers' comments are highly appreciated.

\section{References}

1. Klemas, V.; Bartlett, D.; Philpot, W.; Roger, R. Coastal and estuarine studies with ERTS-1 and Skylab. Remote Sens. Environ. 1974, 3, 153-177.

2. Strong, A.E. Remote sensing of algal blooms by aircraft and satellite in Lake Erie and Utah Lake. Remote Sens. Environ. 1974, 3, 99-107.

3. Lindell, T.; Pierson, D.; Premazzi, G.; Zilioli, E. Manual for Monitoring European Lakes Using Remote Sensing Techniques; EUR 18665 EN; Official Publications of the European Communities: Luxembourg, Luxembourg, 1999.

4. Zhang, Y.; Pulliainen, J.; Koponen, S.; Hallikainen, M. Application of an empirical neural network to surface water quality estimation in the Gulf of Finland using combined optical data and microwave data. Remote Sens. Environ. 2002, 81, 327-336. 
5. Wang, M.H.; Tang, J.; Shi, W. MODIS-derived ocean color products along the China east coastal region. Geophys. Res. Lett. 2007, 34, 1-5.

6. IOCCG (2000). Remote Sensing of Ocean Colour in Coastal, and Other Optically-Complex, Waters; Sathyendranath, S., Ed.; Reports of the International Ocean-Colour Coordinating Group, No.3, IOCCG: Dartmouth, Canada, 2000.

7. Brando, V.E.; Dekker, A.G. Satellite hyperspectral remote sensing for estimating estuarine and coastal water quality. IEEE Trans. Geosci. Remote Sens. 2003, 41, 1378-1387.

8. Lohrenz, S.E.; Cai, W.J.; Chen, X.G.; Tuel, M. Satellite assessment of bio-optical properties of northern Gulf of Mexico coastal waters following hurricanes Katrina and Rita. Sensors 2008, 8, 4135-4150.

9. D'Sa, E.J.; Miller, R.; Del Castillo, C. Bio-optical properties and ocean color algorithms for coastal waters influenced by the Mississippi River during a cold front. Appl. Opt. 2006, 45, 7410-7428.

10. D'Sa, E.J.; Miller, R.; McKee, B. Suspended particulate matter dynamics in coastal waters from ocean color: Application to the northern Gulf of Mexico. Geophys. Res. Lett. 2007, 34, 1-6.

11. Walker, N.D.; Hammack, A.B. Impacts of winter storms on circulation and sediment transport: Atchafalaya-Vermillion Bay Region, Lousiana, USA. J. Coastal Res. 2000, 16, 996-1010.

12. Ruiz, A.; Franco, J.; Orive, E. Suspended particulate matter dynamics in the shallow mesotidal Urdaibai Estuary (Bay of Biscay, Spain). Netherlands J. Aquatic Geol. 1994, 28, 309-316.

13. Gitelson, A.; Schalles, J.; Hladik, C. Remote chlorophyll-a retrieval in turbid, productive estuaries: Chesapeake Bay case study. Remote Sens. Environ. 2007, 109, 464-472.

14. Yang, J.; Chen, C. An optimal algorithm for retrieval of chlorophyll, suspended sediments and gelbstoff of case 2 waters in Zhujiang River estuary. J. Trop. Oceanogr. 2007, 26, 15-20.

15. Chen, X.; Chen, Y.; Lai, G. Modelinig of the transport of suspended solids in the Estuary of Zhujiang River. Acta Oceanol. Sini. 2003, 25, 120-127.

16. Zhu, X.; He, Z.; Meng, D. Remote sensing monitoring of ocean colour in Pearl River estuary. Int. J. Remote Sens. 2002, 23, 4487-4497.

17. Chen, X.; Yuan, Z.; Li, Y.; Wei, Y. Spatial and temporal dynamics of suspended sediment concentration in the Pearl River Estuary based on remote sensing. Geomatics Info. Sci. Wuhan Univ. 2005, 30, 677-681.

18. Chen, C.Q.; Tang, S.; Pan, Z.; Zhan, H.; Larson M.; Jonsson, L. Remotely sensed assessment of water quality levels in the Pearl River Estuary, China. Mar. Pollut. Bull. 2007, 54, 1267-1272.

19. Yin, K.; Qian, P.; Chen, J.; Hsieh, D.; Harrison, P. Dynamics of nutrients and phytoplankton biomass in the Pearl River estuary and adjacent waters of Hong Kong during summer: preliminary evidence for phosphorus and silicon limitation. Mari. Ecol. Progr. Series 2000, 194, 295-305.

20. Yin, K.; Lin, Z.; Ke, Z. Temporal and spatial distribution of dissolved oxygen in the pearl river estuary and adjacent coastal waters. Cont. Shelf Res. 2004, 24, 1935-1948.

21. Dong, L.; Su, J.; Wong, L.; Cao, Z.; Chen, J. Seasonal variation and dynamics of the Pearl River plumes, Conti. Shelf Res. 2004, 24, 1761-1777.

22. Yin, K.; Harrison, P. Influence of the Pearl River estuary and vertical mixing in Victoria Harbor on water quality in relation to eutrophication impacts in Hong Kong waters. Mar. Pollut. Bull. 2007, 54, 646-656. 
23. Gordon, H.R.; Brown, O.B.; Evans, R.H.; Brown, J.; Smith, R.; Baker, K.; Clark, D. A semianalytic radiance model of ocean color. J. Geophys. Res. 1988, 93, 10909-10924.

24. Gitelson, A.; Dall'Olmo, G.; Moses, W.; Rundquist, D.; Barrow, T.; Fisher, T.; Gurlin, D.; Holz, J. A simple semi-analytical model for remote estimation of chloropholl-a in turbid waters: Validation. Remote Sens. Environ. 2008, 112, 3582-3593.

25. Huang, B.; Zhang, L.; Wu, B. Spatio-temporal analysis of rural-urban land conversion. Int. J. Geo. Info. Sci. 2008, in press.

(C) 2009 by the authors; licensee Molecular Diversity Preservation International, Basel, Switzerland. This article is an open-access article distributed under the terms and conditions of the Creative Commons Attribution license (http://creativecommons.org/licenses/by/3.0/). 